\title{
Catalytic effect of carbon nanotubes on polymerization of cyanate ester resins
}

\author{
A. Fainleib ${ }^{1}$, L. Bardash ${ }^{1,2 *}$, G. Boiteux ${ }^{2}$ \\ ${ }^{1}$ Institute of Macromolecular Chemistry of the National Academy of Sciences of Ukraine, 48, Kharkivske shose, 02160 \\ Kyiv, Ukraine \\ 2Université de Lyon, Lyon, F-69003, France ; Université Lyon 1, IMP/LMPB Laboratoire des Matériaux Polymères et \\ Biomatériaux, Bât ISTIL, 43 bd du 11 Novembre, Villeurbanne, F-69622, France ; CNRS, UMR5223, Ingénierie des \\ Matériaux Polymères,Villeurbanne, F-69621, France
}

Received 9 March 2009; accepted in revised form 20 May 2009

\begin{abstract}
Kinetic peculiarities of polycyclotrimerization process of dicyanate ester of bisphenol A (DCBA) in the presence of multi-walled carbon nanotubes (MWCNTs) have been investigated using Fourier Transform Infrared Spectroscopy (FTIR) spectroscopy technique. It has been found that even very small amounts of MWCNTs $(0.01-0.1 \mathrm{wt} \%)$ catalyze the reaction of polycyclotrimerization of DCBA leading to formation of polycyanurate network (PCN)/MWCNTs nanocomposite. However, some decrease in final degree of conversion for nanocomposites compared to the neat PCN within the temperature/time schedule used was observed. The kinetic rate constants increased with addition of MWCNTs and energies of activation were found to be significantly decreased even at low contents of MWCNTs.
\end{abstract}

Keywords: nanocomposites, thermosetting polymers, polycyanurates, carbon nanotubes, sonication

\section{Introduction}

Polycyanurates (PCN) offer a variety of excellent thermal and good mechanical properties, which commend them for use in high performance technology (e.g. as matrices for composites for highspeed electronic circuitry and transportation). For the electronics market, attractive features of PCN are their low dielectric loss characteristics, dimensional stability at molten solder temperatures $\left(220-270^{\circ} \mathrm{C}\right)$, high purity, inherent flame-retardancy (giving the potential to eliminate brominated flame retardants) and excellent adhesion to conductor metals at temperatures up to $250^{\circ} \mathrm{C}$ [1]. Since the late 1970s, cyanate ester resins have been used with glass or aramid fibre in high-speed multilayer circuit boards and this remains their primary application. Several reviews [1-5] collected the numer- ous publications (papers and patents) in the field of PCN synthesis, processing, characterization, modification and application have appeared since 1990s. In addition, like conventional FR-4 diepoxides, cyanate ester laminates retain the desirable (ketone) solution processing characteristics and the ability to be drilled, making it possible to employ them in printed circuit board manufacture. In the last two decades, aerospace composites have evolved into damage-tolerant primary and secondary structures utilizing both thermoset and thermoplastic resins. PCN homopolymers develop approximately twice the fracture toughness of multifunctional epoxies while qualifying for service temperatures of at least $150^{\circ} \mathrm{C}$, intermediate between epoxy and bismaleimides capabilities. PCN have already flown in prototype radomes and high gain antennae, with 


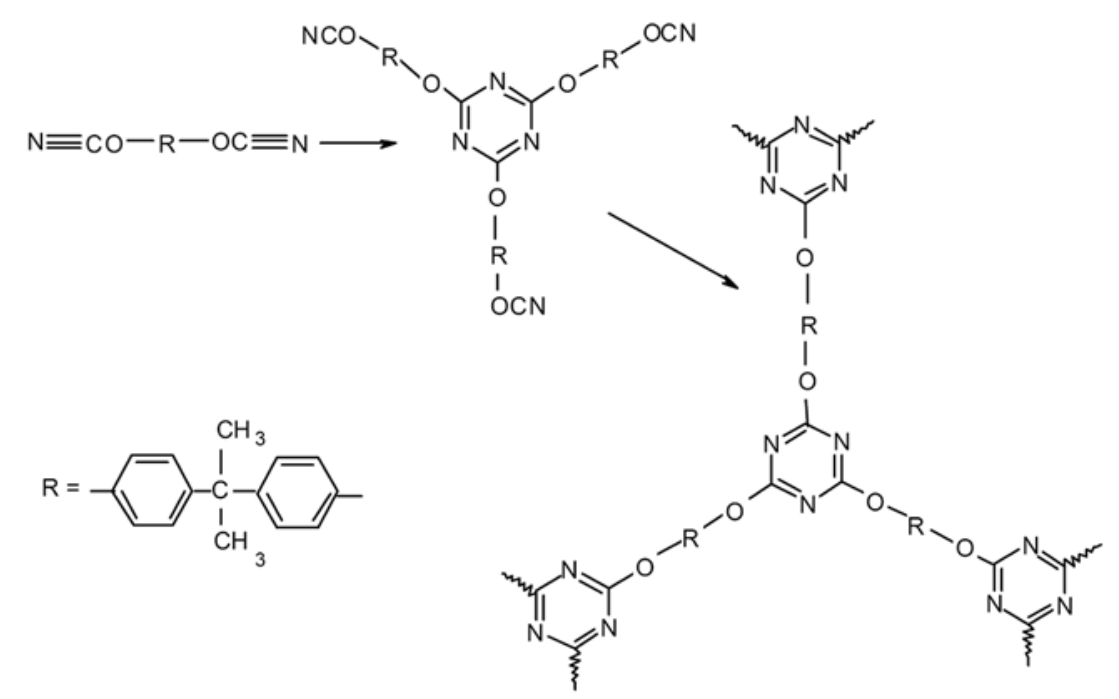

Figure 1. Generalized monomer structure and polycyanurate network formation

possible applications in primary and secondary structures of the High Speed Civil Transport (HSCT) and European Fighter Aircraft. PCN are also being qualified for satellite truss and tube structures and cryogenic, radiation-resistant components in the Superconducting Supercollider [3].

PCN are synthesized by a polycyclotrimerization reaction of cyanate esters (CER) of bisphenols (cf. Figure 1).

In the review [6] the kinetic peculiarities of the homopolycyclotrimerization of cyanate esters (see Figure 1) is analyzed. It is noted that full conversion of the cyanate groups can be achieved at sufficiently high temperature. At this some catalysts are used to accelerate the reaction and to decrease the final temperature of curing. The most popular catalysts are metal acetyl acetonates with nonyl phenol as a co-catalyst.

In our previous works $[7,8]$ at synthesis of polycyanurate/polyurethane semi-IPNs we have found that the polycyclotrimerization process of cyanate esters is accelerated by polyurethane component. Thus the synthesis was carried out without using any traditional catalysts. Recently [9] at synthesis of polycyanurate/montmorillonite (MMT) nanocomposites we have also demonstrated the catalytic effect of MMT on conversion of cyanate groups.

Zhou et al. [10] have reviewed several publications on the effect of unmodified CNTs on the cure reaction of some epoxy systems. The results showed that, at the initial curing stage, MWCNTs act as catalyst and facilitate the curing, moreover, this accel- erating effect is already noticeable at the lowest content of MWCNTs investigated (1 wt $\%$ ).

Few papers were published $[11,12]$ on synthesis of $\mathrm{PCN} / \mathrm{CNTs}$ nanocomposites but no information of kinetic effect of CNTs was reported. Tang et al. [13] described the kinetics of polymerization of the mixture of epoxy resin and cyanate esters with addition of functionalized MWCNTs. Authors explained the catalytic effect of MWCNTs by the presence of hydroxyl groups on CNTs surface that were formed due to their functionalization. No data on catalytic effect of CNTs on polymerization of cyanate esters have been found in the literature.

Logically, we have decided to check if there is any acceleration at polymerization of cyanate ester in the presence of carbon nanotubes (CNTs). Thus the purpose of this work was study of possible catalytic effect of carbon nanotubes on conversion of cyanate groups at synthesis of PCN/CNT nanocomposites

\section{Experimental section}

Pre-polymer of 2,2'-Bis(4-cyanatophenyl)isopropylidene (DCBA) was used for PCN synthesis. DCBA was kindly supplied by Lonza Ltd. as Primaset BADCy (purity $>99 \%$ ) was used as received. The pre-polymer was prepared by heating of DCBA at $150^{\circ} \mathrm{C}$ for $40 \mathrm{~h}$.

MWCNTs were furnished from TM Spetsmash, Kiev, Ukraine. MWVNTs have outer diameter 10 $20 \mathrm{~nm}$, the length is about $100 \mu \mathrm{m}$ and the specific surface is $0,286 \mathrm{~m}^{2} / \mathrm{kg}$. 
The nanocomposites were prepared by sonication of MWCNTs in a liquid pre-polymer at room temperature at $44 \mathrm{~Hz}$ during $45 \mathrm{~min}$ on the ultrasound equipment UZDN-2E. The step by step curing schedule for all the systems consisted of the following stages: $3 \mathrm{~h}$ at $180^{\circ} \mathrm{C}, 1 \mathrm{~h}$ at $210^{\circ} \mathrm{C}, 1 \mathrm{~h}$ at $230^{\circ} \mathrm{C}$, $1 \mathrm{~h}$ at $250^{\circ} \mathrm{C}$. The concentration of MWCNTs was 0.01 and $0.1 \mathrm{wt} \%$. Kinetic peculiarities of the polymerization reaction were studied by using FTIR spectroscopy technique. FTIR measurements were made by a Bruker TENSOR 37 spectrometer in the range of $4000-500 \mathrm{~cm}^{-1}$. The mixture of MWCNTs dispersed in pre-polymer was deposited between two $\mathrm{NaCl}$ windows and the measurements were performed after each stage of curing.

\section{Results and discussion}

The conversion of cyanate groups was determined from changes of absorbance of the band with maximum at $2236-2272 \mathrm{~cm}^{-1}$, corresponding to the valence vibrations of the $-\mathrm{O}-\mathrm{C} \equiv \mathrm{N}$ group. As an internal standard band the band at $2968 \mathrm{~cm}^{-1}$ of the valence vibrations of $\mathrm{CH}_{3}$-group in FTIR spectra of the reactive composition was chosen. On Figure 2 the FTIR spectra of DCBA monomer, DCBA prepolymer and PCN synthesized without using any catalyst are shown. It is seen that at polymerization of the DCBA an intensity of the peaks of cyanate groups at $2236-2272 \mathrm{~cm}^{-1}$ decreases and the peaks

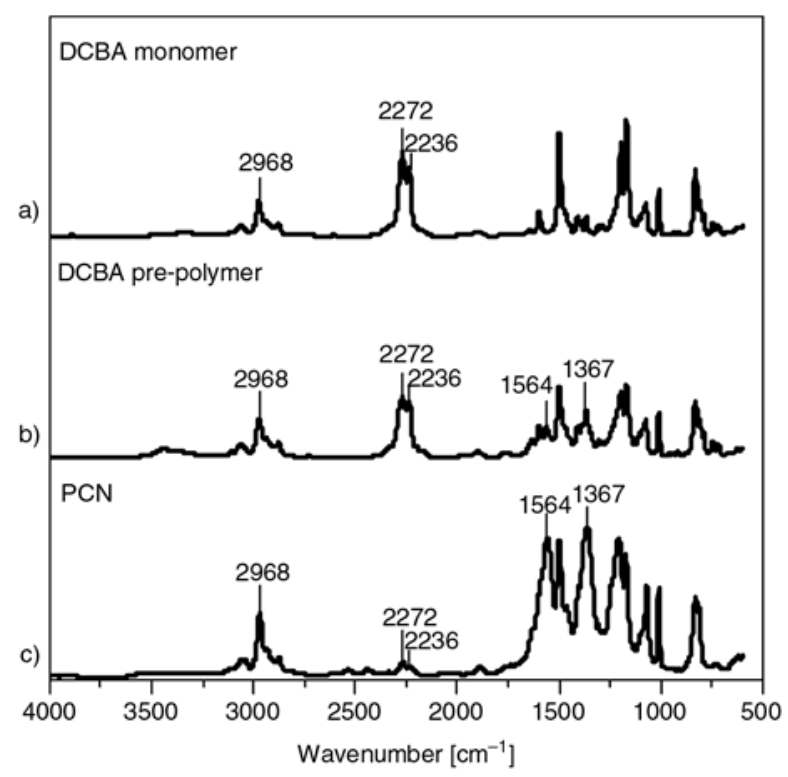

Figure 2. FTIR spectra for a) DCBA monomer; b) DCBA pre-polymer; c) PCN at 1367 and $1564 \mathrm{~cm}^{-1}$ corresponding to polycyanurate cycle [3] appear in the FTIR spectra.

The conversion of resin was calculated using Equation (1):

$\alpha(t)=1-\frac{\frac{A_{(t) 2236-2272}}{A_{(0) 2236-2272}}}{\frac{A_{(t) 2968}}{A_{(0) 2968}}}$

where $A_{(t) 2236-2272}$ is the area under absorbance peak of $-\mathrm{O}-\mathrm{C} \equiv \mathrm{N}$ at $2236-2272 \mathrm{~cm}^{-1}$ at time $t$; $A_{(t) 2968}$ is the area under absorbance peak of $-\mathrm{CH}_{3}$ at $2968 \mathrm{~cm}^{-1}$ at time $t ; A_{(0)}$ are the areas under absorbance peaks of corresponding groups in initial DCBA monomer.

The conversion of cyanate groups in DCBA prepolymer was found to be $28 \%$ and that in PCN sample $-92.5 \%$. It should be noted here that for achieving full conversion post-curing is needed at 270 $300^{\circ} \mathrm{C}$ even at using conventional catalysts [3].

On Figure 3 the conversion of cyanate groups of DCBA pre-polymer as well as in the presence of the small amounts of MWCNTs versus time is shown. The FTIR data evidence an acceleration effect of MWCNTs on kinetics of the early stages of PCN formation. The higher the MWCNTs content in the system the higher the conversion of the cyanate groups into cyanurate cycles at least in the range of the concentrations used. The attempt to study the system with $0.5 \mathrm{wt} \%$ of MWCNTs has led to vitrification as early as in a stage of components blending in 2 min after starting ultrasound action.

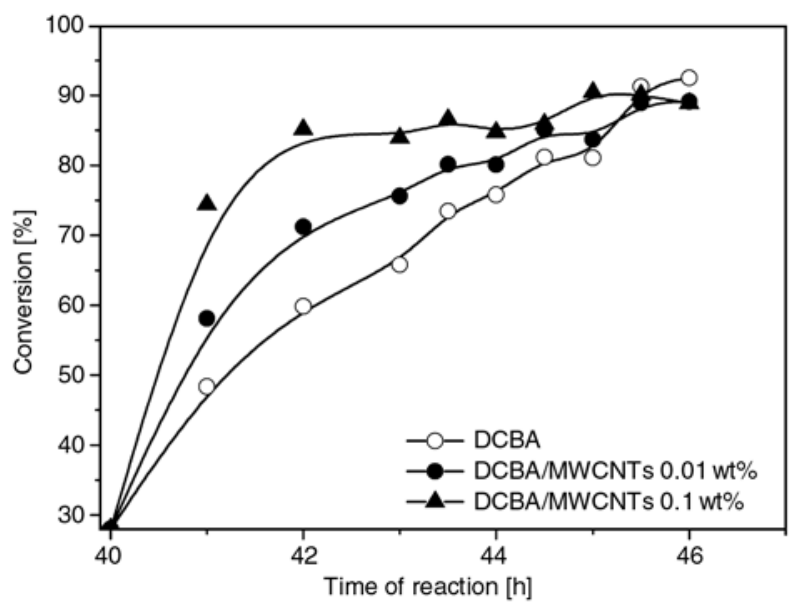

Figure 3. The conversion of DCBA in dependence of reaction time 
Table 1. Effect of MWCNTs content in the reactive composition on final conversion of cyanate groups

\begin{tabular}{|c|c|}
\hline $\begin{array}{c}\text { MWCNTs content } \\
{[\mathbf{w t} \boldsymbol{\%}]}\end{array}$ & $\begin{array}{c}\text { Conversion of -O-C } \equiv \mathbf{C} \text { groups } \\
{[\mathbf{\%}]}\end{array}$ \\
\hline 0 & 92.5 \\
\hline 0.01 & 89.1 \\
\hline 0.10 & 88.8 \\
\hline
\end{tabular}

However, as can be seen from Table 1, in spite of the higher reaction speed of polycyclotrimerization process of the cyanate ester in the presence of MWCNTs the final conversion of $-\mathrm{O}-\mathrm{C} \equiv \mathrm{N}$ groups for the temperature/time schedule used was some lower compared to that for neat PCN.

One can suppose that the acceleration effect of carbon nanotubes on polymerization of cyanate ester is due to adsorption of DCBA pre-polymer molecules on high surface of MWCNTs. However, this phenomenon can play negative role in the final stage of PCN network formation, when some unreacted molecules are not easy accessible, and the probability of elementary reaction act is very low (as can be seen from Figure 1 three molecules of cyanate ester have to meet each other to react with cyanurate cycle formation).

As it was above mentioned this problem can be solved by post-curing of the polymer product at higher temperatures, when the mobility of the reactive molecules and fragments is higher.

The manufacturer of MWCNTs used in this study reports that catalyst residue in MWCNTs is the mixture of $\mathrm{SiO}_{2}, \mathrm{Al}_{2} \mathrm{O}_{3}, \mathrm{Fe}_{2} \mathrm{O}_{3}, \mathrm{MoO}_{3}$. For the moment, there are no references in the literature that describe the catalytic action of such oxides on reaction of cyclotrimerization of cyanate esters. Normally, reaction of cyclotrimerization of the aryl dicyanates can be catalyzed by the mixture of catalyst and co-catalyst. The most common types of catalyst are carboxylate salts and chelates of transition metal ions $\left(\mathrm{Cu}^{2+}, \mathrm{Co}^{2+}, \mathrm{Zn}^{2+}, \mathrm{Mn}^{2+} \ldots\right)$ [3] that facilitate the reaction of cyclotrimerization by formation of co-ordination complexes. The co-catalyst serves a dual purpose of acting as a solvent for catalyst and completing ring closure of the triazine ring via hydrogen transfer. The most commonly used co-catalyst is nonylphenol.

The data obtained from FTIR studies for DCBA and DCBA with 0.01 and $0.1 \mathrm{wt} \%$ of MWCNTs were analyzed using an empirical Equation 2 [3]:

$\frac{\partial \alpha}{\partial t}=k(1-\alpha)^{n}$

where $k$ is the rate constant and $n$ is the order of overall reaction. The parameters $k$ and $n$ are evaluated from the data region where the reaction rate depends on monomer concentration and sharp increase in conversion is observed. Equation (2) was integrated and fitted to experimental concentration profiles of both the unfilled and the filled with MWCNTs systems. It was observed that the data calculated from FTIR spectra is in a good agreement with Equation (2) when the order of reaction $n=1$. This means that DCBA or DCBA/ MWCNTs systems can be described by a firstorder autocatalytic rate law.

The values of the observed rate constants obtained from the first-order reaction analysis for DCBA and DCBA/MWCNTs nanocomposites are listed in the Table 2. The values of kinetic constants for

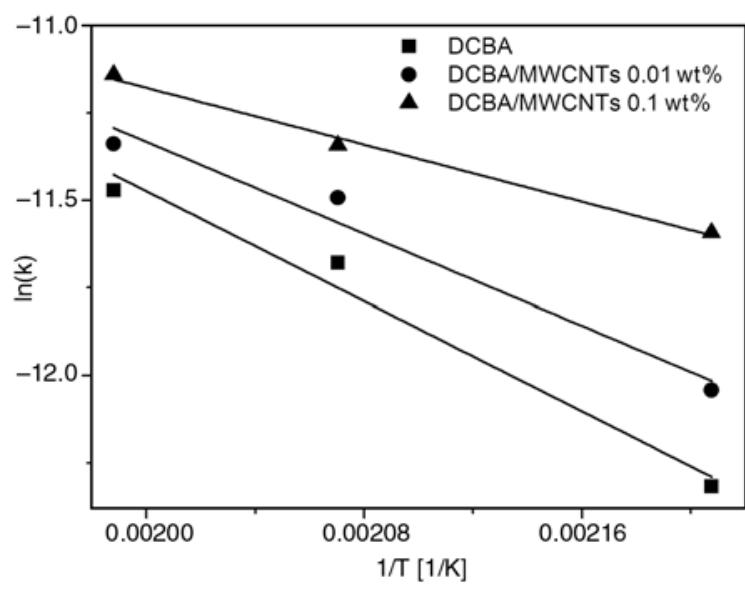

Figure 4. Arrhenius plot for the cure of DCBA and DCBA/MWCNTs

Table 2. Values of the observed rate constants obtained from the first-order reaction analysis for DCBA and DCBA/MWCNTs nanocomposites

\begin{tabular}{|c|c|c|c|}
\hline \multirow{2}{*}{$\begin{array}{c}\text { Temperature } \\
{\left[{ }^{\circ} \mathbf{C}\right]}\end{array}$} & DCBA & DCBA/MWCNTs $\mathbf{0 . 0 1} \mathbf{~ w t} \%$ & DCBA/MWCNTs 0.1 wt\% \\
\cline { 2 - 4 } & 0.02 & 0.02 & 0.02 \\
\hline 150 & 0.05 & 0.06 & 0.09 \\
\hline 180 & 0.08 & 0.10 & 0.12 \\
\hline 210 & 0.10 & 0.12 & 0.14 \\
\hline 230 & &
\end{tabular}


Table 3. Results of the Arrhenius plot of the first-order reaction analysis for DCBA and DCBA/MWCNTs nanocomposites

\begin{tabular}{|c|c|c|}
\hline MWCNTs content [wt $\%]$ & $\mathbf{E}_{\mathbf{a}}[\mathbf{k J} / \mathbf{m o l}]$ & $\operatorname{lnA}\left[\mathbf{s}^{-1}\right]$ \\
\hline 0 & 32.7 & 1.3 \\
\hline 0.01 & 27.3 & 1.6 \\
\hline 0.10 & 16.9 & 2.0 \\
\hline
\end{tabular}

unfilled DCBA are lower than the values reported for the catalyzed DCBA [14]. The results show that the kinetic constant increases with the addition of MWCNTs on each isothermal step of polymerization of DCBA. The activation energies and preexponential factors were determined from Arrhenius plots, shown on Figure 4. A summary of the results is given in Table 3. The activation energies for the reaction ranged from 17 to $33 \mathrm{~kJ} / \mathrm{mol}$ for pure system of DCBA and for the systems filled with MWCNTs and agree with the values reported earlier $[14,15]$. The activation energies for the samples cured with MWCNTs are much lower than the values obtained for virgin DCBA and they decrease with increasing MWCNTs content. This effect is quite similar to the decrease of activation energy with adding catalysts in reactive systems [16].

Presence of low molar mass compounds (for example, conventional catalysts) in polymer networks can influences negatively the thermal properties of the final material. In this work we have shown that synthesis of PCN/CNTs nanocomposites can be effectively realized without using the conventional catalysts.

\section{Conclusions}

The kinetics of polymerization of DCBA and DCBA containing MWCNTs was investigated by FTIR analysis. It was found that the conversion of $-\mathrm{O}-\mathrm{C} \equiv \mathrm{N}$ increases significantly with adding of even small quantities of MWCNTs (e.g. 0.01 and $0.1 \mathrm{wt} \%)$. However, the final degree of reaction for nanocomposites is slightly decreased in comparison with pure PCN matrix. This can be changed by a post-curing procedure. The reaction of DCBA was determined as the first-order autocatalytic reaction. The rate constants were calculated and they were found to be higher for filled systems in comparison to pure DCBA. The obtained data follows the Arrhenius relationship and activation energies estimated from the Arrhenius plots decrease with the addition of MWCNTs. It has been established that due to catalytic effect of MWCNTs on polycyclotrimerization process of cyanate ester resins the polycyanurate/MWCNTs nanocomposites can be synthesized without application of complicated traditional catalytic systems.

\section{References}

[1] Fainleib A. M., Shantalii T. A., Pankratov V. P.: Copolymers of cyanate esters and plastics based on them (in Russian). Polymer Composite Materials, 49, 39-53 (1991).

[2] Fainleib A. M., Sergeeva L. M., Shantalii T. A.: Triazinecontaining interpenetrating polymer networks (in Russian). Polymer Composite Materials, 50, 63-72 (1991).

[3] Hamerton I.: Chemistry and technology of cyanate ester resins. Chapman and Hall, Glasgow (1994).

[4] Hamerton I., Hay J. N.: Recent technological developments in cyanate ester resins. High Performance Polymers, 10, 163-174 (1998).

DOI: $10.1088 / 0954-0083 / 10 / 2 / 001$

[5] Nair C. P. R., Mathew D., Ninan K. N.: Advantages in cyanate ester resins. Advances in Polymer Science, 155, 1-99 (2000). DOI: $10.1007 / 3-540-44473-4 \quad 1$

[6] Bauer M., Bauer J.: Aspects of the kinetics, modeling and simulation of network build-up during cyanate ester cure. in 'Chemistry and technology of cyanate ester resins' (ed.: Hamerton I.) Chapman and Hall, Glasgow, 58-85 (1994).

[7] Fainleib A. M., Novikova T. I., Shantalii T. A., Sergeeva L. M.: Kinetic of formation semi-interpenetrating polymer networks based on crosslinked polycyanurate and linear polyurethane. Polymer Science Series B, 33, 60-67 (1992).

[8] Fainleib A. M., Novikova T. I., Shantalii T. A., Sergeeva L. M.: Synthesis, structure and some properties of the polycyanurate-polyurethane semi-IPNs. Polymeric Materials: Science and Engineering, 66, 131-132 (1992).

[9] Fainleib A. M., Bei I.: Influence of montmorillonite on curing kinetics of dicyanate ester of bisphenol A. Reports of the National Academy of Sciences of Ukraine, 7, 157-161 (2006).

[10] Zhou T., Wang X., Liu X., Xiong D.: Influence of multi-walled carbon nanotubes on the cure behavior of epoxy-imidazole system. Carbon, 47, 1112-1118 (2009).

DOI: $10.1016 /$ j.carbon.2008.12.039

[11] Fang Z., Wang J., Gu A.: Structure and properties of multiwalled carbon nanotubes/cyanate ester composites. Polymer Engineering and Science, 46, 670-679 (2006). DOI: $10.1002 /$ pen.20487 
[12] Hopkins R., Lipeles R. A.: Preparation and characterization of single wall carbon nanotube-reinforced polycyanurate nanocomposites. Polymer Preprints, 46, 787 (2005).

[13] Tang Y-S., Kong J., Gu J-W., Liang G-Z.: Reinforced cyanate ester resins with carbon nanotubes: Surface modification, reaction activity and mechanical properties analyses. Polymer-Plastics Technology and Engineering, 48, 359-366 (2009).

DOI: $10.1080 / 03602550902725340$
[14] Li W., Ling G., Xin W.: Triazine reaction of cyanate ester resin systems catalyzed by organic tin compound: Kinetics and mechanism. Polymer International, 53, 869-876 (2004).

DOI: $10.1002 /$ pi.1446

[15] Osei-Owusu A., Martin G. C., Gotro J. T.: Catalysis of cyclotrimerization of cyanate ester resin systems. Polymer Engineering and Science, 32, 535-541 (1992).

DOI: $10.1002 /$ pen.760320805

[16] Carey F. A., Sundberg R. J.: Advanced organic chemistry- Part A: Structure and Mechanisms. Springer Verlag, Berlin (2007). 